Article

\title{
Preparation and Enhanced Isothermal Oxidation Resistance of a Low Diffusivity NiRePtAl Single-Phase Coating
}

\author{
He Liu ${ }^{1,2, *}$, Erqi Yang ${ }^{1}$, Cean Guo ${ }^{3}$, Quan Liu ${ }^{1}$, Lanlan Yang ${ }^{4}$ and Zebin Bao ${ }^{5}$ (D) \\ 1 School of Materials Science and Engineering, Sheyang Ligong University, Shenyang 110159, China; \\ yeq03257@163.com (E.Y.); qliu@sylu.edu.cn (Q.L.) \\ 2 Science and Technology Development Corporation, Shenyang Ligong University, Shenyang 110159, China \\ 3 School of Equipment Engineering, Sheyang Ligong University, Shenyang 110159, China; \\ guo1122332022@126.com \\ 4 School of Materials Science and Engineering, Jiangsu University of Science and Technology, \\ Zhenjiang 212003, China; lanlanyang@just.edu.cn \\ 5 Institute of Metal Research, Chinese Academy of Sciences, Shenyang 110016, China; zbbao@imr.ac.cn \\ * Correspondence: liu13898134531@163.com
}

check for updates

Citation: Liu, H.; Yang, E.; Guo, C.; Liu, Q.; Yang, L.; Bao, Z. Preparation and Enhanced Isothermal Oxidation Resistance of a Low Diffusivity NiRePtAl Single-Phase Coating. Coatings 2022, 12, 114. https:// doi.org/10.3390/coatings12020114

Received: 27 December 2021

Accepted: 17 January 2022

Published: 20 January 2022

Publisher's Note: MDPI stays neutral with regard to jurisdictional claims in published maps and institutional affiliations.

Copyright: (C) 2022 by the authors. Licensee MDPI, Basel, Switzerland. This article is an open access article distributed under the terms and conditions of the Creative Commons Attribution (CC BY) license (https:// creativecommons.org/licenses/by/ $4.0 /)$.

\begin{abstract}
A low diffusivity NiRePtAl single-phase coating was formed on a $\mathrm{Ni}_{3} \mathrm{Al}$-based SC superalloy by electroplating and aluminizing treatments, in which the electroplating consisted of depositing $\mathrm{Ni}$-Re and Pt layer. The isothermal oxidation test of the sample was evaluated at 1100 and $1200{ }^{\circ} \mathrm{C}$; the results indicated that the low diffusivity NiRePtAl single-phase sample promoted the oxidation resistance due to a greater $\beta-\mathrm{NiAl}$ phases-enriched outer layer. The Re-base diffusion barrier could effectively refrain the outward diffusion of Mo. Low diffusivity NiRePtAl single-phase coating has a lower inter-diffusion rate to the superalloy, where the thickness of the secondary reaction zone decreased by $35 \%$. Mechanisms responsible for improved oxidation resistance and decreased extent for the formation of secondary reaction zones are discussed in the present study.
\end{abstract}

Keywords: Pt-modified aluminide coating; isothermal oxidation; interdiffusion; corrosion

\section{Introduction}

The single-phase NiPtAl coating, as standalone coating or bond coat of the thermal barrier coating (TBC) system, is one of the widely applied protective coatings for gas turbines in aerospace and marine due to its outstanding high-temperature oxidation and hot corrosion resistance, along with excellent thermo-fatigue properties [1-5]. A continuous, adherent, slow-growing protective $\mathrm{Al}_{2} \mathrm{O}_{3}$ scale, which acts as a barrier against oxidation and hot corrosive attack, is usually formed at the surface of the NiPtAl coating once exposed to high temperatures. However, serious interdiffusion occurs from both sides of the coating. The diffusion of aluminum from the coating reacts with $\mathrm{O}_{2}$ in the air to form the $\mathrm{Al}_{2} \mathrm{O}_{3}$ film. On the other hand, an interdiffusion zone (IDZ) grows in the matrix by diffusion of aluminum from the bond coating to the superalloy, which causes great consumption of $\mathrm{Al}$ and leads the phase transformation from $\beta$-NiAl to $\gamma^{\prime}-\mathrm{Ni}_{3} \mathrm{Al}$ [6-8]. The high-temperature oxidation property of the NiPtAl coating thus decreases to a large extent. Moreover, the loss of $\mathrm{Ni}$ from the superalloy destroys the coherent structure of the matrix and leads to the growth of the topologically close-packed (TCP) phase, which is rich in W, Mo, Re, etc. The TCP precipitates are the sources of mechanical failure [8-10].

Preparing a diffusion barrier (DB) layer on the substrate is a crucial way to inhibit the interdiffusion. Many reports are available regarding both metallic and ceramic DBs. Yao et al. [11] prepared a NiCrO interlayer and confirmed that it can act as active DB, and the DB layer changed to a triple sandwich layer in the oxidation experiments. Similarly, Guo et al. [12] prepared a YSZ interlayer and found that it can suppress interdiffusion between

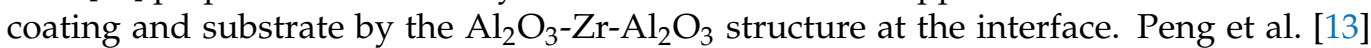


deposited an oxide dispersed NiCoCrAlY coating on SC superalloy by adding O during preparation and found that the outward diffusion of elements (hafnium, chromium, and rhenium) had been usefully alleviated by the coating with $\mathrm{O}$.

Although ceramic diffusion barriers can inhibit the elemental diffusion between coatings and superalloy and retard the formation of the inter-diffusion zone and secondary reaction zone (SRZ) in substrate effectively, the natural brittleness and weak elasticity of ceramic DB led the susceptibility to crack, which may finally cause the spallation of the whole coating. In addition, the bond strength between the ceramic diffusion barriers and substrate/coatings is generally weak, because the thermal expansion coefficient between ceramic diffusion barriers and metallic substrate/coating is comparably large. Compared with ceramics DBs, metal DBs are an alternative due to their superior ductility and flexibility and strong bonding with substrate/coating, especially for rhenium. It has been proven to be suitable as a diffusion barrier layer to inhibit the interdiffusion between the coating and superalloy [14-16]. Mercier et al. [17] prepared an Re-based diffusion barrier layer for TBC systems; the coating with the Re-base diffusion barrier layer had better oxidation resistance.

However, the report of the Re-base DB layer inhibiting interdiffusions between NiPtAl coating and matrix is rare, especially for operation temperatures up to $1200{ }^{\circ} \mathrm{C}$. In the present paper, a Ni-Re film as DB layer for NiPtAl coating was added at the interface of the NiPtAl coating and $\mathrm{Ni}_{3} \mathrm{Al}$-base substrate. Compared with regular NiPtAl coating, isothermal oxidation performance has been more widely researched; the effects of the diffusion barrier interlayer on the oxidation and interdiffusion performance at 1100 and $1200{ }^{\circ} \mathrm{C}$ were studied.

\section{Materials and Methods}

\subsection{Coating Preparation}

A bar of $\mathrm{Ni}_{3} \mathrm{Al}$-base single crystal (SC) superalloy (6-7 wt.\% Al, 12-14 wt.\% Mo, 1-3 wt.\% Re, balanced Ni) was used as matrix material. The specimens, in size of $\Phi 15 \times 2 \mathrm{~mm}$, were cut from an ingot. They were then grounded with 400 \# SiC papers, blasted with $\mathrm{Al}_{2} \mathrm{O}_{3}$ grits, then cleaned ultrasonically in a solution of ethanol and acetone for $30 \mathrm{~min}$.

The NiRePtAl coating was formed by electro-deposition and vapor phase aluminizing treatments. A $5-8 \mu \mathrm{m} \mathrm{Ni}$-Re layer was electroplated on the $\mathrm{Ni}_{3} \mathrm{Al}$-base matrix in the solution made of $\mathrm{NiSO}_{4} \cdot 6 \mathrm{H}_{2} \mathrm{O}, \mathrm{NaCl}, \mathrm{H}_{2} \mathrm{BO}_{3}, \mathrm{Na}_{2} \mathrm{SO}_{4}, \mathrm{C}_{12} \mathrm{H}_{25} \mathrm{NaSO}_{4}$ and $\mathrm{KReO}_{4}$, and the $\mathrm{pH}$ value of the solution was 5. A 5-7 $\mu \mathrm{m}$ Pt layer was electroplated on the rhenium layer, followed by a vacuum annealing treatment at $1050^{\circ} \mathrm{C}$ for one hour; then, the vapor phase aluminizing experiment was carried out at $1070^{\circ} \mathrm{C}$ for $4.5 \mathrm{~h}$. For a detailed description of the electroplating and vaper phase aluminizing process, refer to our recent work [18]. For comparison, the NiPtAl coating was formed by electroplating of platinum and vapor phase aluminizing treatments.

\subsection{Oxidation Tests}

Isothermal oxidation experiments were performed at $1100^{\circ} \mathrm{C}$ for $500 \mathrm{~h}$ and $1200{ }^{\circ} \mathrm{C}$ for $200 \mathrm{~h}$. The corundum crucibles containing samples to be experimented on were put into a furnace, in which the temperature had already risen to 1100 or $1200{ }^{\circ} \mathrm{C}$, and were fetched out of the crucibles after a particular oxidation time for weight measurement by an electron balance with a sensitivity of $10^{-5} \mathrm{~g}$.

\subsection{Characterization}

The phase constituents of the two coatings were analyzed using X-ray diffraction (XRD, $X^{\prime}$ Pert PRO, Cu K $\alpha$ radiation at $40 \mathrm{KV}$, PANalytical, Almelo, The Netherlands). Surface and cross-sectional morphologies were observed using scanning electron microscopy (SEM, InspectF 50, FEI Co., Hillsboro, OR, USA) with an energy dispersive spectrometer (EDS, INCA, X-Max, Oxford instruments Co., Oxford, UK). A second electron (SE) mode was used to characterize the surface morphology, while the cross-sectional morphologies were ob- 
served under back scattered electron (BSE) mode. An electron probe micro-analyzer (EPMA, JXA-8530 F, JEOL, Tokyo, Japan) was employed to characterize the elemental distribution.

\section{Results}

\subsection{Initial Microstructure of Coatings}

Figure 1 shows the surface and cross-sectional morphologies of the as-received NiPtAl and low diffusivity NiRePtAl coatings. It should be found from Figure $1 \mathrm{a}, \mathrm{b}$ that the NiPtAl and low diffusivity NiRePtAl coatings presented similar surface morphologies. From the cross-sectional morphology, it can be noted from Figure 1c that the NiPtAl coating sample consisted of two layers: the outer zone comprising the $\beta$ phase with the thickness of $40 \mu \mathrm{m}$ and IDZ $(30 \mu \mathrm{m})$ containing TCP particles. The cross-sectional morphology seen in Figure 1d shows that the NiRePtAl coating was composed of three layers: the outer zone, the DB layer and IDZ. The intermediate DB consisted of the Re rich layer; the thickness was about $8 \mu \mathrm{m}$. Due to the diffusion inhibition effect of DB, the thickness of the outer layer and IDZ was reasonably thinner compared with the NiPtAl coating, at 32 and $20 \mu \mathrm{m}$, respectively. It should be noted that, at the interface between the diffusion barrier and the interdiffusion zone, some dark $\mathrm{Al}_{2} \mathrm{O}_{3}$ grits can be observed, in which this interface represented the surface of the substrate after sandblasting.
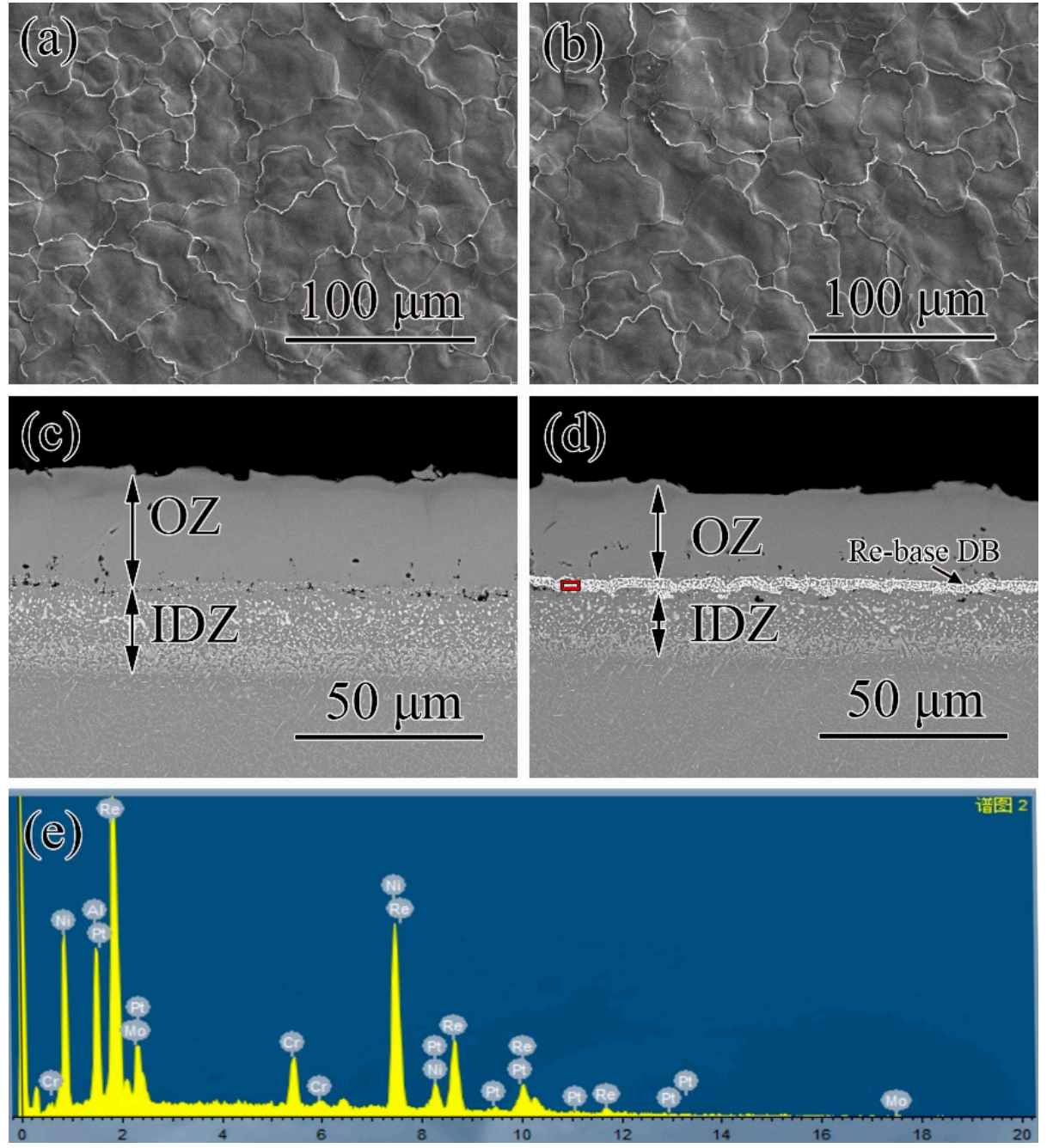

Figure 1. Surface and cross-sectional morphologies of the as-received normal $\mathrm{NiPtAl}(\mathbf{a}, \mathbf{c})$ and low diffusivity NiRePtAl (b,d) coatings and the Re-base DB EDS result (e). 
Figure 2 depicts the X-ray diffraction patterns for the NiPtAl and low diffusivity $\mathrm{NiRePtAl}$ coatings. It can be observed that both coating specimens were composed of exclusive $\beta-\mathrm{NiAl}$; the angles of diffraction peaks were identical, which indicated that the introduction of the Re layer did not transform the phase constitution of the NiPtAl sample.

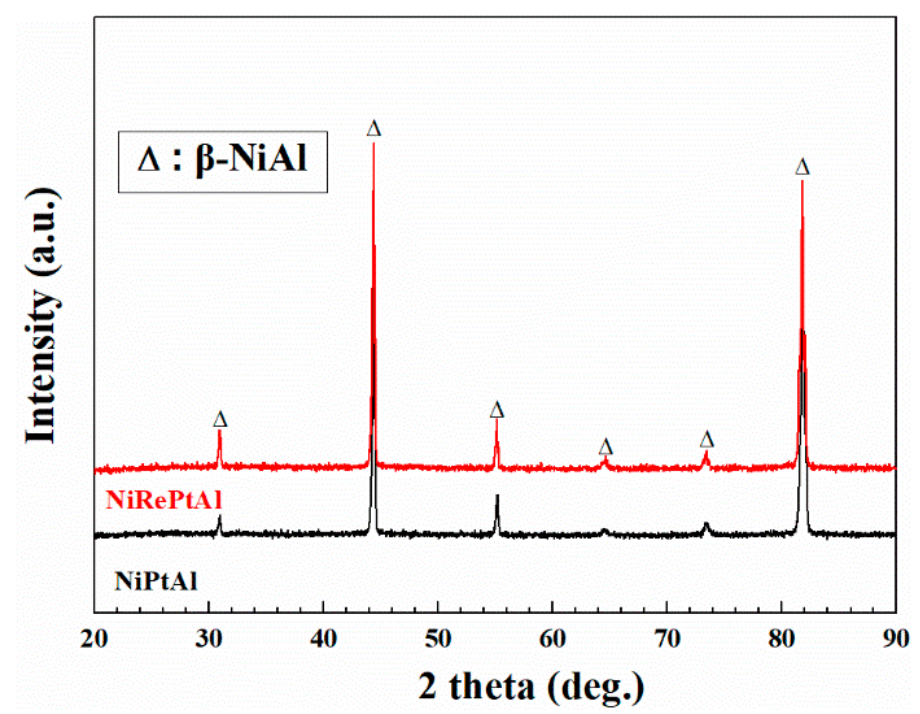

Figure 2. X-ray diffraction patterns of the as-received normal NiPtAl and low diffusivity NiRePtAl specimens.

\subsection{Isothermal Oxidation Behavior at $1100{ }^{\circ} \mathrm{C}$}

Figure 3 shows weight gain and square of weight gain curves for the NiPtAl and low diffusivity NiRePtAl coating specimens during isothermal oxidation at $1100{ }^{\circ} \mathrm{C}$ for $500 \mathrm{~h}$. It can be seen from Figure $3 \mathrm{a}$ that the mass increased rapidly for both samples at the initial oxidation step. While in the stable stage, the curves of the two coatings fit the parabolic law, showing that the two coating specimens had good isothermal oxidation resistance. However, the low diffusivity NiRePtAl coating specimen showed a lower oxidation rate, where the weight gain at $500 \mathrm{~h}$ was $0.29 \mathrm{mg} / \mathrm{cm}^{2}$, in comparison with $0.60 \mathrm{mg} / \mathrm{cm}^{2}$ for $(\mathrm{Ni}, \mathrm{Pt}) \mathrm{Al}$. Figure $3 \mathrm{~b}$ shows that the square of the weight gain of $(\mathrm{Ni}, \mathrm{Pt}) \mathrm{Al}$ and $\mathrm{NiRePtAl}$ accorded with the fitted line completely. The oxidation rate constants $\left(\mathrm{k}_{\mathrm{p}}\right)$ were acquired by regressing the data illustrated in Figure $3 \mathrm{~b}$. During the stable oxidation stage, $\mathrm{k}_{\mathrm{p}}$ values for NiRePtAl and NiPtAl specimens were $2.17 \times 10^{-4}$ and $6.44 \times 10^{-4} \mathrm{mg}^{2} \mathrm{~cm}^{-4} \mathrm{~h}^{-1}$. The results indicated the helpful effect of the Re-rich diffusion barrier on oxidation resistance, which reduced the parabolic rate of oxide film growth by a factor of 3 .

Figure 4 depicts the cross-sectional morphologies of the (Ni,Pt)Al and low NiRePtAl samples after the isothermal oxidation test at $1100^{\circ} \mathrm{C}$ for $500 \mathrm{~h}$. As shown in Figure $4 \mathrm{a}$, the $\mathrm{Al}_{2} \mathrm{O}_{3}$ scale on the surface of the NiPtAl specimen was not adhered; spallation occurred at some locations. Furthermore, a severe interdiffusion was observed in the matrix. The thickness of IDZ was approximately $40 \mu \mathrm{m}$; large precipitates were dispersed in the interdiffusion zone. Beneath the IDZ, the thickness of the secondary reaction zone was $82 \mu \mathrm{m}$, with a large number of needle-like TCP phases, which was considered to be detrimental to high-temperature mechanical properties of the superalloy. In contrast, the $\mathrm{Al}_{2} \mathrm{O}_{3}$ film on the surface of NiRePtAl was adherently continuous without spallation (see Figure $4 \mathrm{~b}$ ). The thickness of the interdiffusion zone was $40 \mu \mathrm{m}$, which is similar to that in the NiPtAl sample. However, the thickness of the secondary reaction zone beneath NiRePtAl was only $51 \mu \mathrm{m}, 38 \%$ lower than that of the NiPtAl specimen. In addition, the EDS results of rectangles 1 and 2 listed in Table 1 confirm that the residual aluminum content in the outer layer of $\mathrm{NiRePtAl}$ was higher than the content in the same depth of $(\mathrm{Ni}, \mathrm{Pt}) \mathrm{Al}$, which indicated that the oxidation resistance of $\mathrm{NiRePtAl}$ can be better than $(\mathrm{Ni}, \mathrm{Pt}) \mathrm{Al}$ if oxidation 
continued. The EDS results of zone 3 confirmed that the DB layer was not only rich with $\mathrm{Re}$, but also rich with $\mathrm{Cr}$.
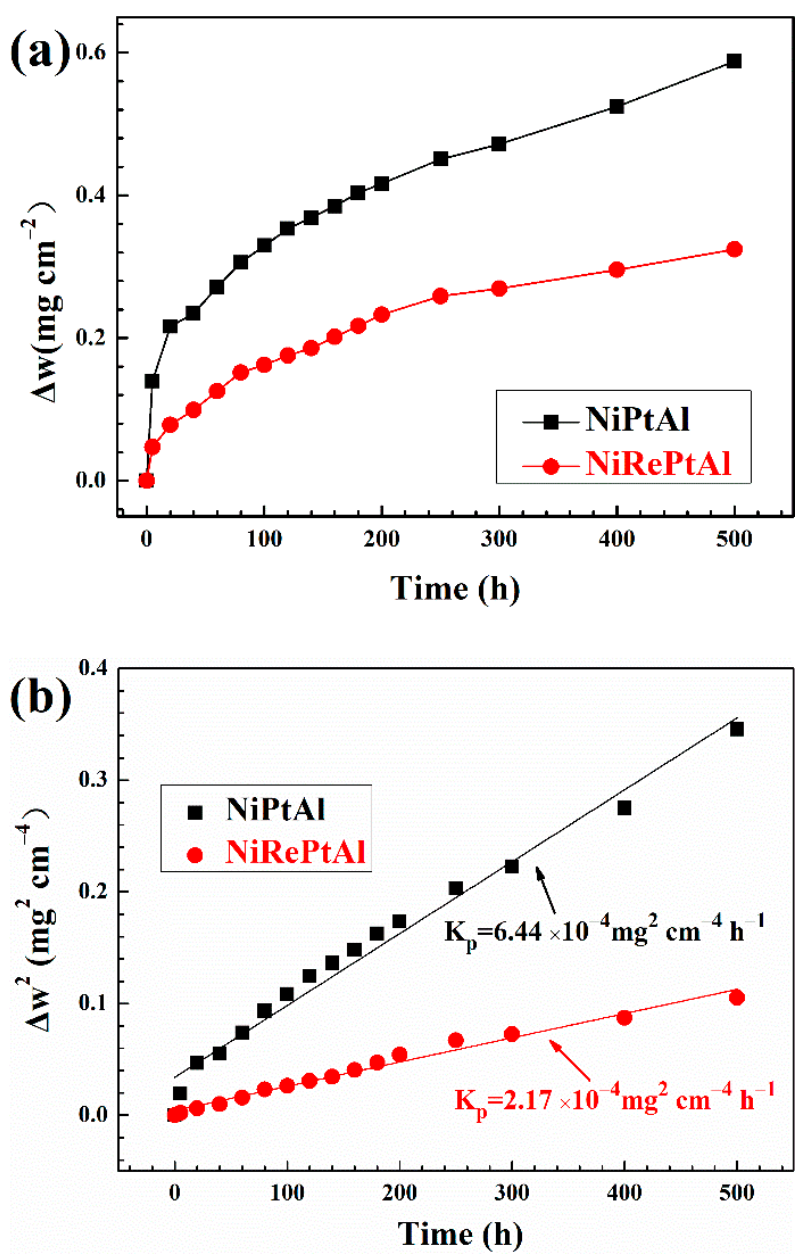

Figure 3. Mass gain (a) and square of mass gain (b) for the normal NiPtAl and low diffusivity $\mathrm{NiRePtAl}$ coating specimens during the isothermal oxidation test at $1100{ }^{\circ} \mathrm{C}$.
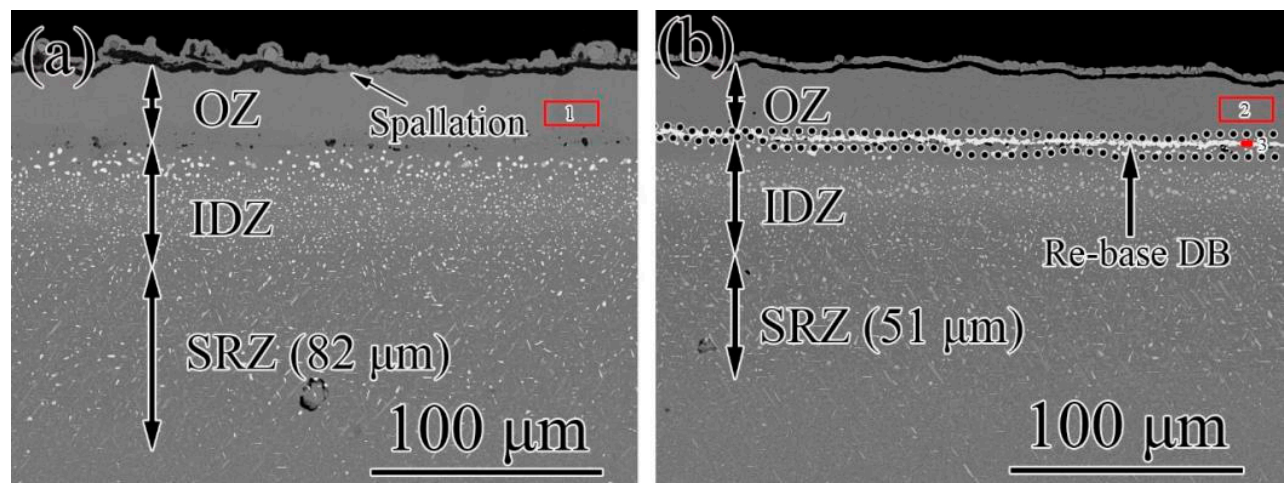

Figure 4. Cross-sectional morphologies of the normal NiPtAl (a) and low diffusivity NiRePtAl (b) coating specimens after isothermal oxidation test at $1100{ }^{\circ} \mathrm{C}$ for $500 \mathrm{~h}$. 
Table 1. Chemical compositions of the marked areas in Figure 4 (in at.\%) by EDS.

\begin{tabular}{ccccccc}
\hline At. $\%$ & Al & Cr & Ni & Mo & Pt & Re \\
\hline 1 & 30.12 & 3.42 & 60.73 & 0.91 & 4.82 & 0 \\
2 & 33.26 & 3.15 & 58.56 & 0 & 5.03 & 0 \\
3 & 4.24 & 14.13 & 29.24 & 30.04 & 0 & 22.35 \\
\hline
\end{tabular}

In order to further shed light on the elemental distribution of both coatings after oxidation for 500 h, EPMA mapping was conducted, as shown in Figures 5 and 6. Comparing Figure 5 with Figure 6, there were three differences in the elemental distribution. First, a continuous Re-rich band existed at the interface of the outer zone and interdiffusion zone in NiRePtAl, while not in NiPtAl. Second, Mo did not diffuse outward into the outer layer in NiRePtAl; however, small amounts of Mo diffused into the outer layer even into the oxide scale. Last, as some Al-deficiency areas existed in the outer zone of the NiPtAl coating, the residual $\mathrm{Al}$ content in $\mathrm{NiRePtAl}$ was clearly larger than that in $\mathrm{NiPtAl}$, which was coincident with the EDS results listed in Table 1.

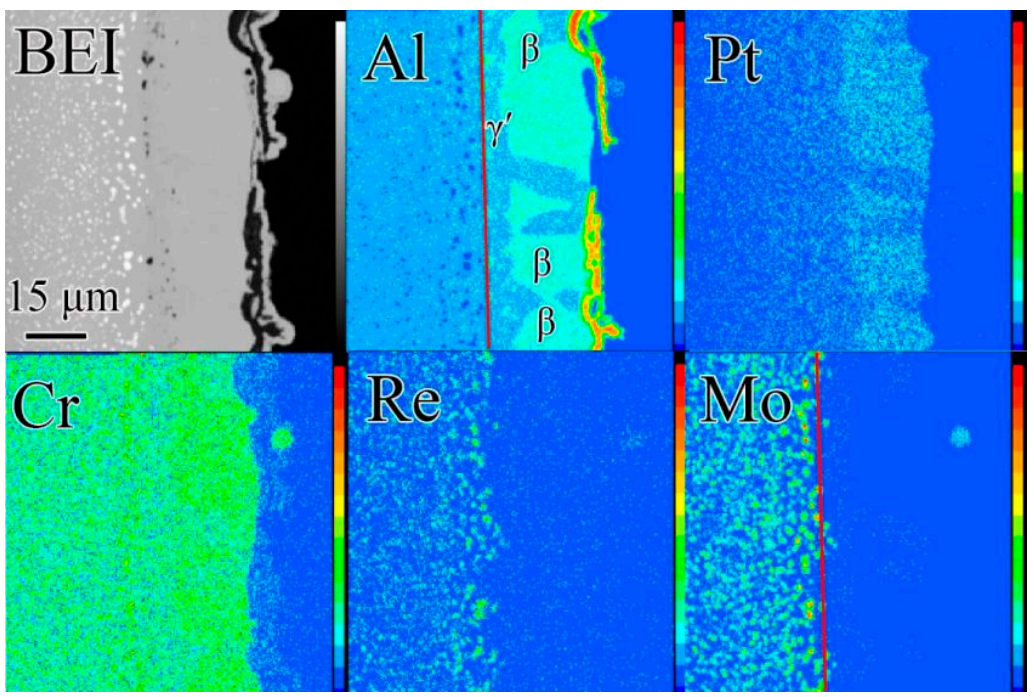

Figure 5. Elemental mappings of the normal NiPtAl coating after isothermal oxidation test at $1100{ }^{\circ} \mathrm{C}$ for $500 \mathrm{~h}$.

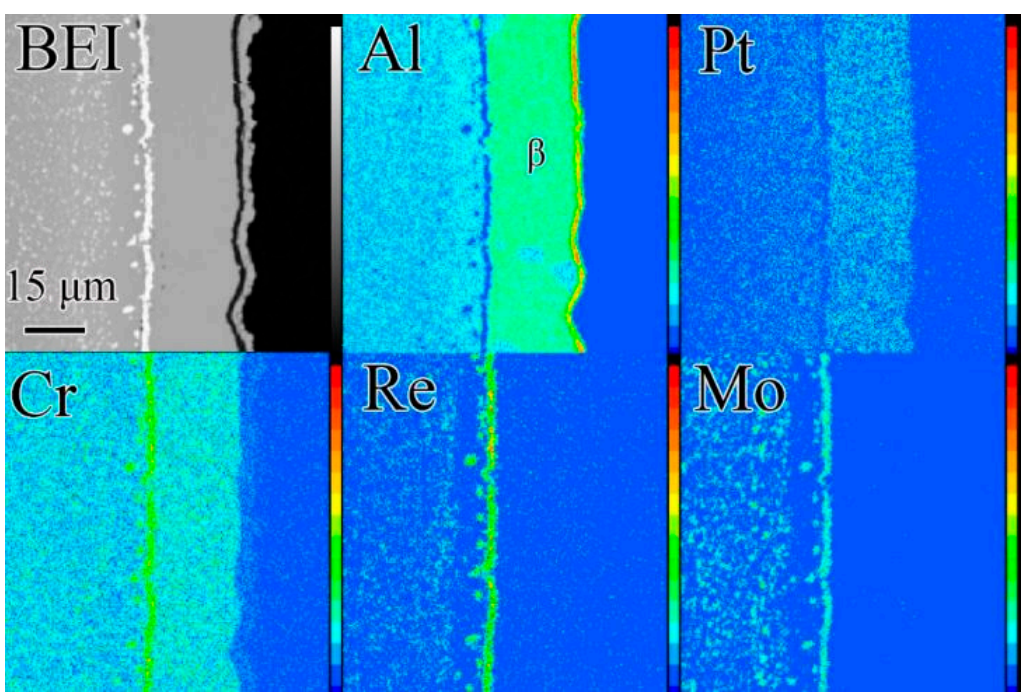

Figure 6. Elemental mappings of the low diffusivity NiRePtAl coating specimen after isothermal oxidation test at $1100{ }^{\circ} \mathrm{C}$ for $500 \mathrm{~h}$. 


\subsection{Isothermal Oxidation Behavior at $1200^{\circ} \mathrm{C}$}

Figure 7 shows mass gain curves of both samples during the isothermal oxidation experiments at $1200^{\circ} \mathrm{C}$. The weight gain of the NiRePtAl coating increased in an approximately parabolic manner with time. However, the mass gain of NiPtAl coating increased in a straight-line pattern with time; the final total mass gain of NiRePtAl was $0.52 \mathrm{mg} \mathrm{cm}^{-2}$, which was approximately $35 \%$ lower than that of the NiPtAl coating $\left(0.80 \mathrm{mg} \mathrm{cm}^{-2}\right)$. The mass gain of both coatings oxidized at $1200^{\circ} \mathrm{C}$ was generally much larger than that oxidized at $1100^{\circ} \mathrm{C}$.

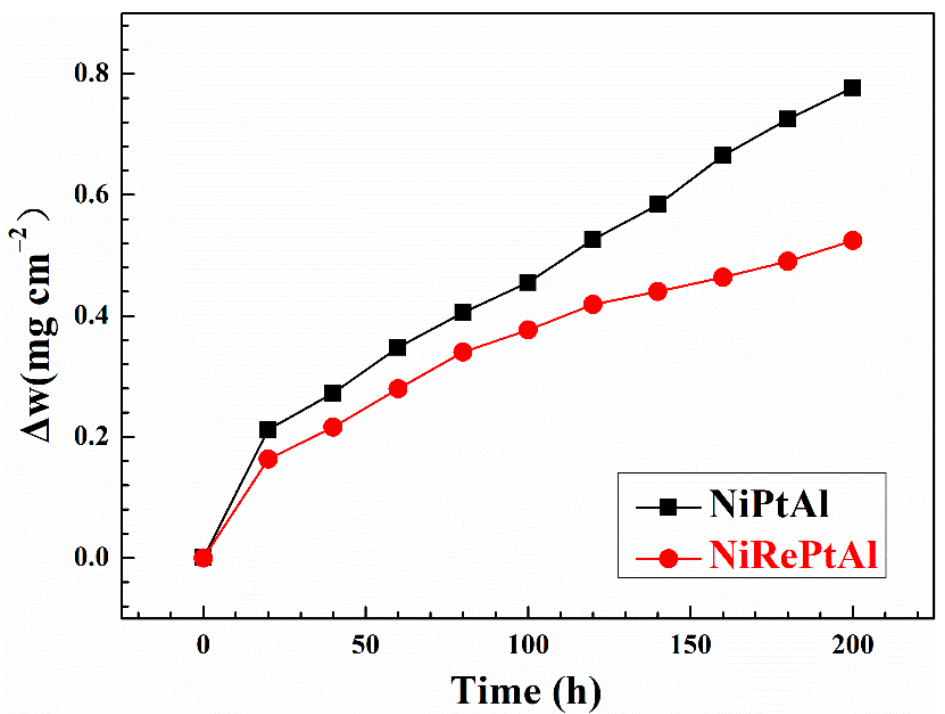

Figure 7. Mass gain for the normal NiPtAl and low diffusivity NiRePtAl coating specimens during isothermal oxidation test at $1200{ }^{\circ} \mathrm{C}$.

Figure 8 depicts the surface morphologies of NiPtAl and NiRePtAl specimens after oxidation for $100 \mathrm{~h}$. Spallation of the $\mathrm{Al}_{2} \mathrm{O}_{3}$ scale happened locally on the (Ni,Pt)Al coating specimen (Figure 8a). From the high-magnification image, the spallation can be observed more clearly. When a DB layer was introduced, no spallation of the scale was seen in NiRePtAl (Figure 8b,d); however, some pores were observed in the scale based on the magnified image.

Figure 9 depicts the cross-sectional morphologies of the NiPtAl and low NiRePtAl samples after oxidation test at $1200{ }^{\circ} \mathrm{C}$ for $100 \mathrm{~h}$. Comparing the two coatings, three differences were noted. First, the $\mathrm{Al}_{2} \mathrm{O}_{3}$ scales on the NiPtAl specimen were full of cracks and spallation, while adherent oxide scales were observed on the NiRePtAl sample. Second, from the aspect of coatings composition, the Al contents in the same depth of the outer zone of the NiPtAl and NiRePtAl specimens were 26.42 and 30.93 at.\% in Table 2, respectively. Al loss was inevitable during oxidation because of the outwards diffusion to form oxide film or interdiffusion between the high-temperature protective coating and matrix; moreover, it would be better to preserve high aluminum content in the protective coatings. In addition, the content of molybdenum in the outer zone of the NiRePtAl specimen was less than the Mo content in NiPtAl, which indicated that the Re diffusion barrier layer inhibited the diffusion of molybdenum in the matrix. Third, although the IDZ thickness of both coatings after oxidation for $100 \mathrm{~h}$ was comparable, $42 \mu \mathrm{m}$ for NiPtAl and $40 \mu \mathrm{m}$ for NiRePtAl, respectively, the secondary reaction zone thickness of NiPtAl $(92 \mu \mathrm{m})$ was much larger than the thickness of NiRePtAl $(55 \mu \mathrm{m})$. Much greater amounts of needle-shaped TCP precipitated out for NiPtAl compared with NiRePtAl. 

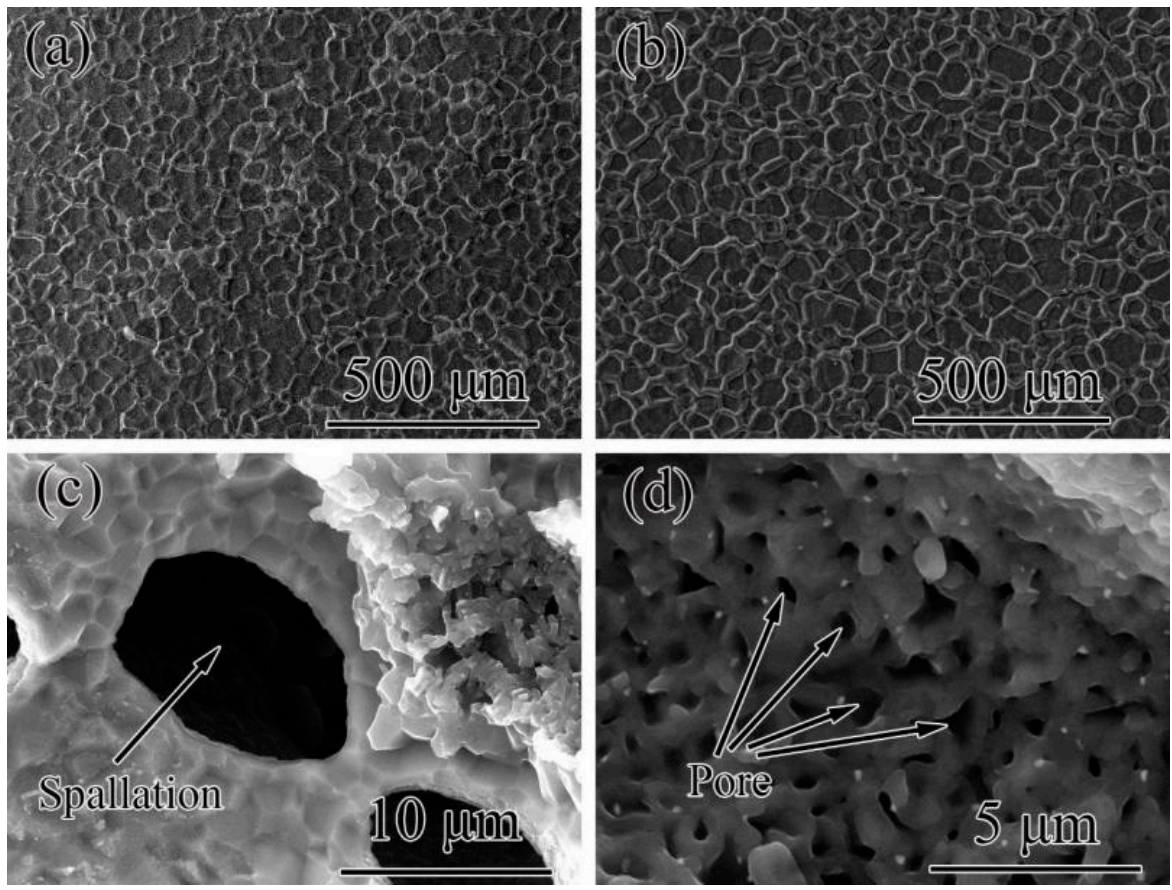

Figure 8. Surface morphologies of the normal $\operatorname{NiPtAl}(\mathbf{a}, \mathbf{c})$ and low diffusivity $\mathrm{NiRePtAl}(\mathbf{b}, \mathbf{d})$ after isothermal oxidation test at $1200{ }^{\circ} \mathrm{C}$ for $100 \mathrm{~h}$.
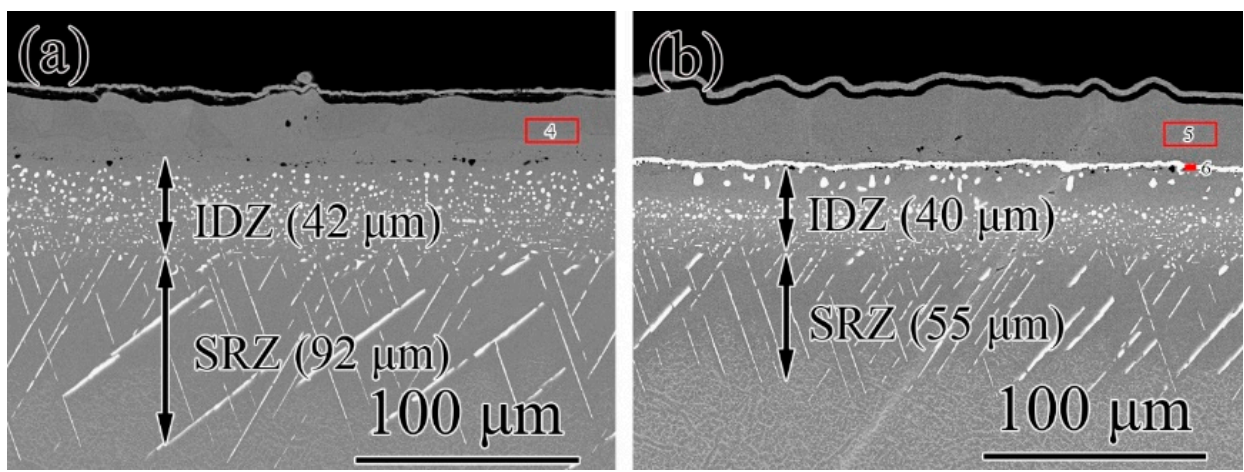

Figure 9. Cross-sectional morphologies of the normal $\mathrm{NiPtAl}$ (a) and low diffusivity $\mathrm{NiRePtAl}$ (b) coating specimens after isothermal oxidation test at $1200^{\circ} \mathrm{C}$ for $100 \mathrm{~h}$.

Table 2. Chemical compositions of the marked areas in Figure 9 (in at.\%) by EDS.

\begin{tabular}{ccccccc}
\hline At. $\%$ & Al & Cr & Ni & Mo & Pt & Re \\
\hline 4 & 26.42 & 2.17 & 64.25 & 2.86 & 4.30 & 0 \\
5 & 30.93 & 1.77 & 62.99 & 0.33 & 3.98 & 0 \\
6 & 6.13 & 10.15 & 25.87 & 32.17 & 0 & 25.68 \\
\hline
\end{tabular}

Surface and cross-sectional morphologies of specimens at $1200{ }^{\circ} \mathrm{C}$ for $200 \mathrm{~h}$ are shown in Figures 10 and 11. As shown in Figure 10a,b, compared with oxidation for $100 \mathrm{~h}$, much more spallation occurred on the NiPtAl coating. For the NiRePtAl coating, the oxide scale was smoother, but still full of pores based on magnified morphology. Figure 11 showed the $\mathrm{Al}_{2} \mathrm{O}_{3}$ film was thicker for both samples after $200 \mathrm{~h}$, and more spallation occurred on the PtAl coating, while only a bit spallation happened locally on the surface of NiRePtAl. It should be noted that, although the weight gain of the NiPtAl sample was more significant than the NiRePtAl sample for $200 \mathrm{~h}$, the oxide film formed at the $\mathrm{NiPtAl}$ coating was thinner based on the cross-sectional morphologies. This is because a 
substantial amount of spallation occurred for NiPtAl when specimens were taken out from the furnace. The coating composition showed a similar pattern with that for $100 \mathrm{~h}$. The aluminum concentration in the same depth of the outer area of the NiPtAl and NiRePtAl specimens were $24.18 \%$ and $30.36 \%$ in Table 3, respectively. The content of Mo in the outer zone of the NiRePtAl sample was less than the Mo content in NiPtAl. Again, the IDZ thickness of both coatings was comparable, $36 \mu \mathrm{m}$ for NiPtAl and $34 \mu \mathrm{m}$ for NiRePtAl, respectively, but the SRZ thickness of NiPtAl $(150 \mu \mathrm{m})$ was much larger than the thickness of NiRePtAl $(97 \mu \mathrm{m})$. A much greater amount of needle-shaped TCP precipitated out for NiPtAl compared with NiRePtAl.
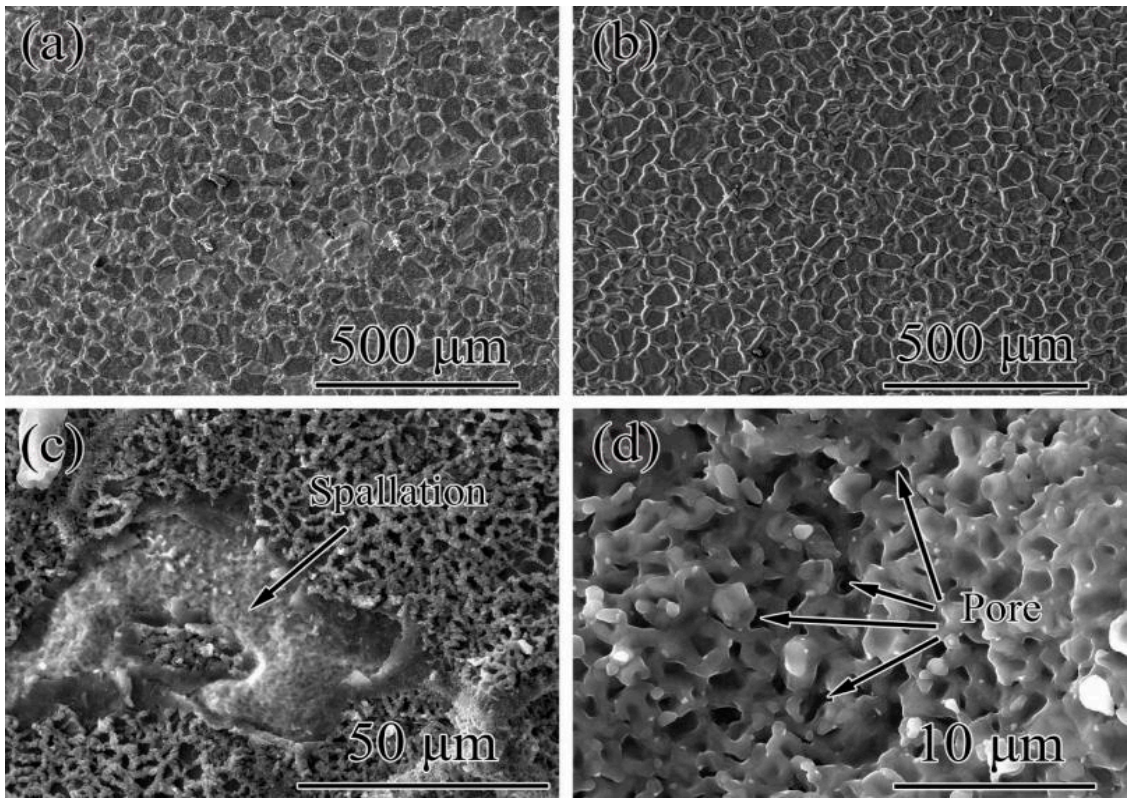

Figure 10. Surface morphologies of the normal $\mathrm{NiPtAl}(\mathbf{a}, \mathbf{c})$ and low diffusivity $\mathrm{NiRePtAl}(\mathbf{b}, \mathbf{d})$ coatings after isothermal oxidation test at $1200{ }^{\circ} \mathrm{C}$ for $200 \mathrm{~h}$.
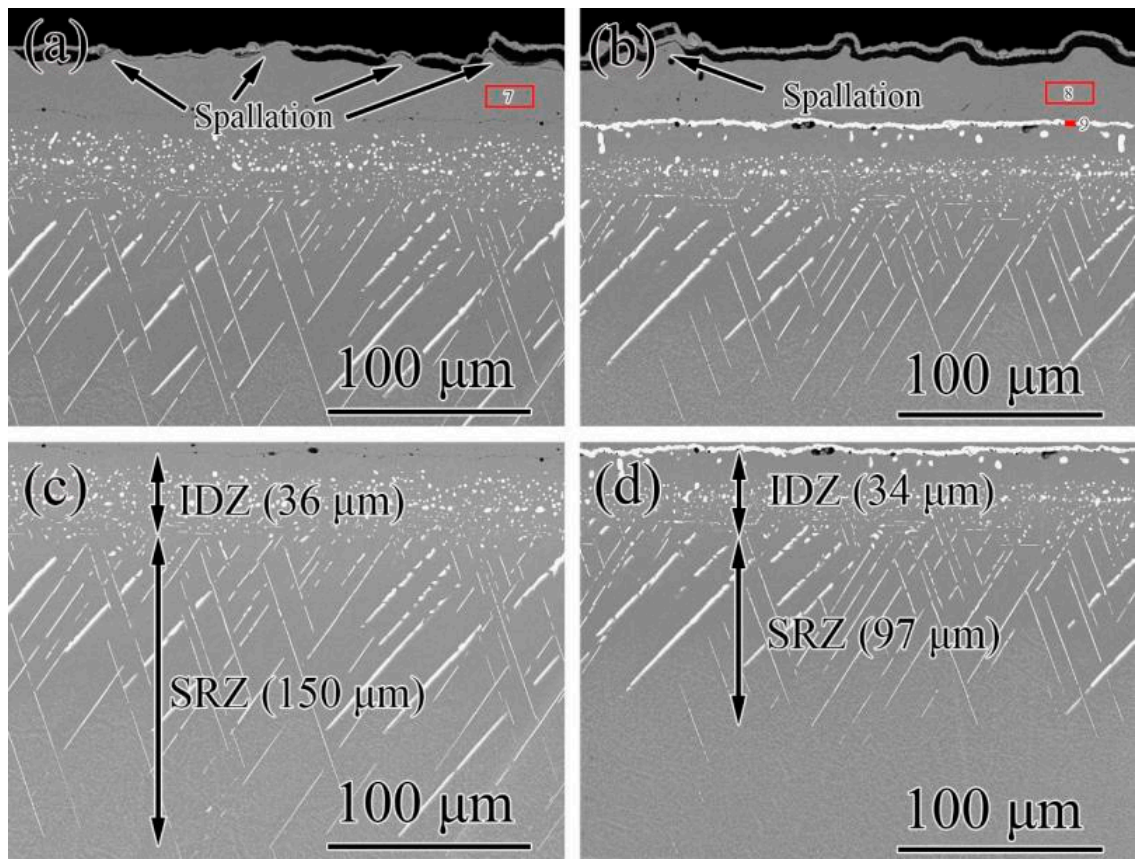

Figure 11. Cross-sectional morphologies of the normal $\mathrm{NiPtAl}(\mathbf{a}, \mathbf{c})$ and low diffusivity $\mathrm{NiRePtAl}$ (b,d) coating specimens after isothermal oxidation test at $1200{ }^{\circ} \mathrm{C}$ for $200 \mathrm{~h}$. 
Table 3. Chemical compositions of the marked areas in Figure 11 (in at.\%) by EDS.

\begin{tabular}{ccccccc}
\hline At. $\%$ & Al & Cr & Ni & Mo & Pt & Re \\
\hline 7 & 24.18 & 4.65 & 63.86 & 3.19 & 4.12 & 0 \\
8 & 30.36 & 2.07 & 61.81 & 1.48 & 4.28 & 0 \\
9 & 3.26 & 8.15 & 29.23 & 36.22 & 0 & 23.14 \\
\hline
\end{tabular}

\section{Discussion}

The oxidation behavior of NiRePtAl was superior to the conduct of NiPtAl at both 1100 and $1200{ }^{\circ} \mathrm{C}$. The discussion starts from the effect of the Re-base diffusion barrier layer on inhibiting the outward diffusion of Mo, then the impact of the $\mathrm{DB}$ layer on $\mathrm{Al}_{2} \mathrm{O}_{3}$ film growth and interdiffusion, e.g., SRZ formation will be discussed.

\subsection{The Effect of DB Layer on Inhibiting Mo Outward Diffusion}

$\mathrm{Ni}_{3} \mathrm{Al}$-based SC superalloy contained a high concentration of Mo. The gaseous molybdenum oxide at 1100 and $1200^{\circ} \mathrm{C}$ should be noticed. Standard Gibbs free energy changes $\left(\Delta \mathrm{G}_{\theta}\right)$ to compose $\mathrm{MoO}_{3}$ can be computed by Equation (1), as shown below,

$$
\Delta \mathrm{G}_{\theta}=-359800+59.41 \mathrm{~T}
$$

Calculated from Equation (1), the standard Gibbs energy change of $\mathrm{MoO}_{3}$ production is negative at 1100 and $1200{ }^{\circ} \mathrm{C}$ [19], which shows that the behavior happens spontaneously during isothermal oxidation. For the NiPtAl coating without the DB layer, Mo can diffuse into the high-temperature coating and $\mathrm{Al}_{2} \mathrm{O}_{3}$ scale easily (see Figure 5). When the $\mathrm{MoO}_{3}$ was composed on the scale, it reduced the scale adhesion and retarded the oxidation resistance, especially at $1200^{\circ} \mathrm{C}$. Mo diffuses outward more rapidly and the volatile products are formed more easily, which explains partly why the spallation of the NiPtAl specimen at $1200{ }^{\circ} \mathrm{C}$ was more serious than that at $1100^{\circ} \mathrm{C}$. However, in the case of NiRePtAl with the DB layer, the situation is restrained by the DB layer; the reaction of Equation (1) and formation of the $\mathrm{MoO}_{3}$ is inhibited. Therefore, an adherent $\mathrm{Al}_{2} \mathrm{O}_{3}$ scale was composed at the NiRePtAl coating.

\subsection{The Effect of DB Layer on Oxide Scale Growth}

Compared with the NiPtAl coating, the weight change curve for the NiRePtAl sample presented a lower oxidation rate (see Figures 3 and 7), especially at $1200{ }^{\circ} \mathrm{C}$; the weight gain of the NiPtAl fit almost in a straight-line pattern with time, while NiRePtAl coating enhanced in an around parabolic manner. The thickness of the $\mathrm{Al}_{2} \mathrm{O}_{3}$ scale on NiRePtAl was more integrated than the thickness of NiPtAl (Figures 4, 9 and 11). The $\mathrm{Al}_{2} \mathrm{O}_{3}$ was firstly composed of the $\mathrm{Al}$ in the coating and $\mathrm{O}$ in the air, resulting in the $\mathrm{Al}_{2} \mathrm{O}_{3}$ scale formed in the initial stage. Then, in the stable oxidation stage, the kinetic curves of the $\mathrm{NiPtAl}$ and NiRePtAl coatings fit parabolic pattern well at $110{ }^{\circ} \mathrm{C}$, indicating that the scale growth is dominated by solid diffusion in the oxide film. However, at $1200{ }^{\circ} \mathrm{C}$, the weight gain of the NiPtAl fit almost in a straight-line pattern, indicating that the scale growth was not dominated by solid diffusion again. During oxidation, the consumption of benefit element $\mathrm{Al}$ generally results from the phase transformation from $\beta-\mathrm{NiAl}$ to $\gamma^{\prime}-\mathrm{Ni}_{3} \mathrm{Al}$ and meaningless interdiffusion with the matrix. Actually, in the current work, the formation of aluminum oxide film expended a limited amount of aluminum for the samples because the $\mathrm{Al}_{2} \mathrm{O}_{3}$ film was very thin. The consumption of $\mathrm{Al}$ is mainly attributed to the interdiffusion. However, less interdiffusion occurred due to the Re-base DB in the NiRePtAl coating. Therefore, sufficient high content of $\mathrm{Al}$ in the outer zone was reserved. The $\beta$ reservoir possesses the ability to supply aluminum to form/repair the $\alpha-\mathrm{Al}_{2} \mathrm{O}_{3}$ scale once crack or spallation takes place. This also explains why the spallation of NiPtAl is much more severe than the NiRePtAl coating, besides the formation of volatile $\mathrm{MoO}_{3}$, as mentioned above. The effect of the $\mathrm{DB}$ layer on oxide scale growth can be attributed to the characteristic that 
it inhibits aluminum diffused inwardly into the matrix in vain, thus, keeping the coating's strong self-repairing capability.

\subsection{The Effect of BD Layer on SRZ Formation}

As a matter of fact, a lot of previous work [20-23] is available concerning the interdiffusion behavior between diffusion aluminide coatings and superalloy matrix. Many factors have a great effect on the interdiffusion behavior, including crystal orientation [24,25], stress induced by surface treatment [25], alloy constitution [20,22] and so on. P and $\mu$ are the two dominant TCPs in SRZ [26,27]. Kasai et al. [28] studied the interdiffusion behavior of aluminide coatings on SC TMS- 138 at $1100{ }^{\circ} \mathrm{C}$, and found three interdiffusion features between the IDZ and the matrix: voids, secondary diffusion zone (SDZ) and SRZ. Almost all TCPs in SDZ precipitated in the $\gamma$-Ni phase, so the constitution of SDZ was because the outward diffusion of nickel was faster than any other element in the matrix. It is usually hard to distinguish SDZ and SRZ, and SDZ can transform to SRZ. Wang et al. [26] found an interesting phenomenon that the initial-formed SDZ transformed into secondary reaction zone in the NiAlHf coating at annealing treatment. Das et al. [23] found that the secondary reaction zone formation was attributed to the discontinuous cellular precipitation, and Nystrom et al. [29] found that the primary driving forces of discontinuous cellular precipitation are the high degree of supersaturation of refractory elements in the $\gamma / \gamma^{\prime}$ matrix. The supersaturation of elements (like $\mathrm{Re}, \mathrm{Cr}$ and Mo) results in the formation of the TCP phase, which lead to the formation of IDZ followed by SRZ.

Figure 12 presented the evolution of SRZ of NiPtAl sample. A model for secondary reaction zone formation in NiPtAl coated SC superalloy is presented:

(a) During the treatment of aluminization, the $\gamma / \gamma^{\prime}$ coherent structure was broken and transformed into $\beta$ phasel; due to the diffusion fluxes of aluminum from NiPtAl coating to the $\mathrm{Ni}_{3} \mathrm{Al}$-base matrix and that of nickel in the opposite direction. Because the solid solubility of molybdenum [30], tungsten [31] and rhenium [32] in $\beta$ and $\gamma^{\prime}$ is lower than in $\gamma$, and the diffusion mobility of these refractory elements is much slower than $\mathrm{Ni}, \mathrm{Co}, \mathrm{Al}[33]$, refractory elements will precipitate out as TCP phase, as shown in Figure 12a.

(b) The TCP precipitates in the interdiffusion zone are quite fine at the beginning, and then they congregated after oxidation at 1100 and $1200^{\circ} \mathrm{C}$ [34,35], as shown in Figure $12 \mathrm{~b}$. The IDZ zone grow thicker due to continuous interdiffusion fluxes of aluminum and nickel.

(c) As the interdiffusion occurs for a certain time, the chemical potential gradients of $\mathrm{Al}$ and Ni decreased at the IDZ growth frontier. Meanwhile, TCP precipitates dispersed in IDZ had the blocking effect of Al and Ni diffusion. Thus, the $\gamma / \gamma^{\prime} \rightarrow \beta$ was replaced by $\gamma / \gamma^{\prime} \rightarrow \gamma^{\prime}$. When the diffusion fluxes of $\mathrm{Al}$ and $\mathrm{Ni}$ become too low to support the interdiffusion zone growth, SRZ is formed. The $\beta \rightarrow \gamma / \gamma^{\prime}$ transformation at the interface of the IDZ/SRZ, and the $\beta / \gamma^{\prime}$ interface will enter the outer coating.

As illustrated schematically in Figure 12, in the NiPtAl sample, a wide secondary reaction zone was formed at high temperature, which for sure could deteriorate the mechanical properties of the matrix. In contrast, both the diffusion of aluminum and the elements in matrix were inhibited by the Re diffusion barrier. Fewer amounts of interdiffusions are helpful to stabilize the structure of matrix. Moreover, fewer TCP phases will form in the substrate, leading to thinner formation of secondary reaction zone. 

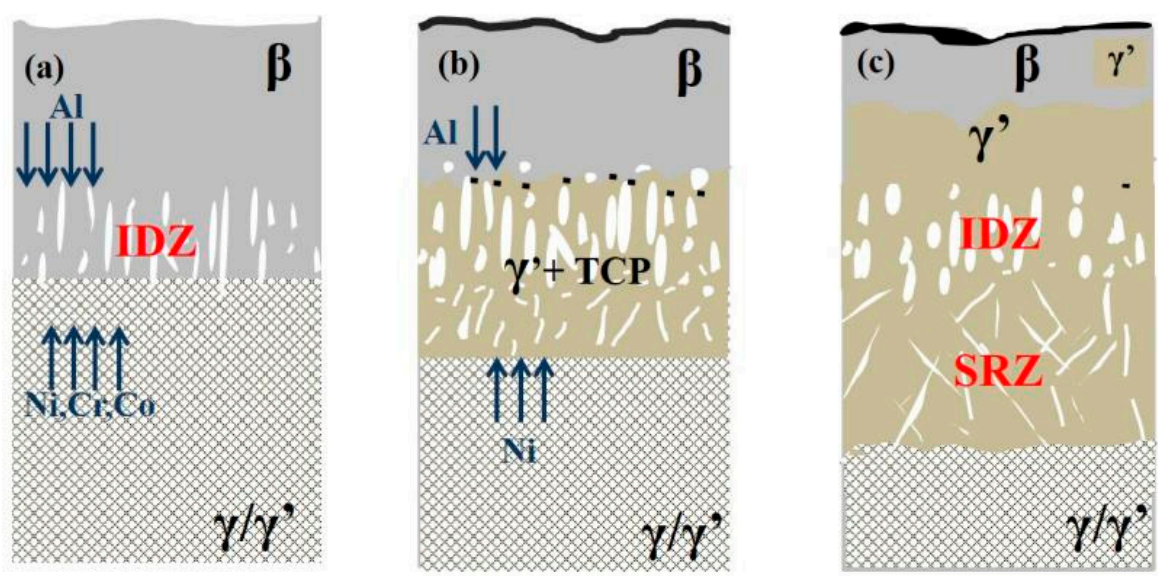

Figure 12. Schematic illustration showing evolution of SRZ developed below normal NiPtAl coating: (a) during the treatment of aluminization, (b) after $20 \mathrm{~h}$ oxidation at 1100 and $1200^{\circ} \mathrm{C}$, (c) after $200 \mathrm{~h}$ oxidation at 1100 and $1200{ }^{\circ} \mathrm{C}$.

\section{Conclusions}

Isothermal oxidation behavior of low diffusivity NiRePtAl single-phase coating was evaluated in comparison with NiPtAl coatings at 1100 and $1200{ }^{\circ} \mathrm{C}$. The following conclusions can be drawn based on the experimental results:

(1) Low diffusivity NiRePtAl single-phase coatings exhibited superior oxidation performance than NiPtAl coatings, both at 1100 and $1200{ }^{\circ} \mathrm{C}$.

(2) The outward diffusion of molybdenum was restrained due to the Re-based diffusion barrier.

(3) The elemental interdiffusion was significantly restrained by the Re diffusion barrier layer, in which the thickness of secondary reaction zone and the amount of TCP phase were notably reduced.

Author Contributions: Writing—original draft preparation, methodology, investigation, H.L.; data curation, E.Y.; conceptualization, resource, C.G.; writing-review and editing, funding acquisition, H.L.; supervision, Q.L., L.Y. and Z.B. All authors have read and agreed to the published version of the manuscript.

Funding: This work was supported by the National Natural Science Foundation of China (Grant Nos.52101090 and 52001142), and the Supporting Project of Middle-young Aged Innovative Talents of Science and Technology of Shenyang City (RC190292, and RC210483), and the supporting Project of Innovative Talents of Colleges and Universities of Liaoning Province (LR2019059), and the Basic Research Project of Education Department of Liaoning Province of China (No. LG202020).

Institutional Review Board Statement: Not applicable.

Informed Consent Statement: Not applicable.

Data Availability Statement: Not applicable.

Conflicts of Interest: The authors declare that they have no known competing financial interests or personal relationships that could have appeared to influence the work reported in this paper.

\section{References}

1. Yang, Y.F.; Jiang, C.Y.; Bao, Z.B.; Zhu, S.L.; Wang, F.H. Effect of aluminisation characteristics on the microstructure of single phase beta-(Ni,Pt)Al coating and the isothermal oxidation behaviour. Corros. Sci. 2016, 106, 43-54. [CrossRef]

2. Jiang, C.; Qian, L.; Feng, M.; Liu, H.; Bao, Z.; Chen, M.; Zhu, S.; Wang, F. Benefits of Zr addition to oxidation resistance of a sin-gle-phase (Ni,Pt)Al coating at 1373 K. J. Mater. Sci. Technol. 2019, 35, 1334-1344. [CrossRef]

3. Song, Y.; Murakami, H.; Zhou, C. Cyclic-Oxidation Behavior of Multilayered Pt/Ru-Modified Aluminide Coating. J. Mater. Sci. Technol. 2011, 27, 280-288. [CrossRef] 
4. Yu, C.T.; Liu, H.; Jiang, C.Y.; Bao, Z.B.; Zhu, S.L.; Wang, F.H. Modification of NiCoCrAlY with Pt: Part II. Application in TBC with pure metastable tetragonal $\left(\mathrm{t}^{\prime}\right)$ phase YSZ and thermal cycling behavior. J. Mater. Sci. Technol. 2019, 35, 350-359. [CrossRef]

5. Divya, V.D.; Ramamurty, U.; Paul, A. Effect of Pt on interdiffusion and mechanical properties of the $\gamma$ and $\gamma^{\prime}$ phases in the Ni-Pt-Al system. Philos. Mag. 2012, 92, 2187-2214. [CrossRef]

6. Paul, A.; Kodentsov, A.A.; van Loo, F.J.J. On diffusion in the $\beta$-NiAl phase. J. Alloys Compd. 2005, 403, 147-153. [CrossRef]

7. Peng, X.; Jiang, S.; Gong, J.; Sun, X.; Sun, C. Preparation and Hot Corrosion Behavior of a NiCrAlY + AlNiY Composite Coating. J. Mater. Sci. Technol. 2016, 32, 587-592. [CrossRef]

8. Liu, H.; Li, S.; Jiang, C.Y.; Yu, C.T.; Bao, Z.B.; Zhu, S.L.; Wang, F.H. Preparation and oxidation performance of a low-diffusion Pt-modified aluminide coating with Re-base diffusion barrier. Corros. Sci. 2020, 168, 108582. [CrossRef]

9. Kiruthika, P.; Paul, A. A pseudo-binary interdiffusion study in the $\beta-N i(P t) A l$ phase. Philos. Mag. Lett. 2015, 95, 138-144. [CrossRef]

10. Liu, H.; Xu, M.; Li, S.; Bao, Z.; Zhu, S.; Wang, F. Improving cyclic oxidation resistance of Ni3Al-based single crystal superalloy with low-diffusion platinum-modified aluminide coating. J. Mater. Sci. Technol. 2020, 54, 132-143. [CrossRef]

11. Yao, H.; Bao, Z.; Shen, M.; Zhu, S.; Wang, F. A magnetron sputtered microcrystalline $\beta$-NiAl coating for SC superalloys. Part II. Effects of a NiCrO diffusion barrier on oxidation behavior at $1100^{\circ} \mathrm{C}$. Appl. Surf. Sci. 2017, 407, 485-494. [CrossRef]

12. Guo, C.; Wang, W.; Cheng, Y.; Zhu, S.; Wang, F. Yttria partially stabilised zirconia as diffusion barrier between NiCrAlY and Ni-base single crystal René N5 superalloy. Corros. Sci. 2015, 94, 122-128. [CrossRef]

13. Peng, H.; Guo, H.; He, J.; Gong, S. Cyclic oxidation and diffusion barrier behaviors of oxides dispersed NiCoCrAlY coatings. J. Alloys Compd. 2010, 502, 411-416. [CrossRef]

14. Wang, L.; Gorr, B.; Christ, H.-J.; Mukherji, D.; Rösler, J. The effect of alloyed nickel on the short-term high temperature oxidation behaviour of Co-Re-Cr-based alloys. Corros. Sci. 2015, 93, 19-26. [CrossRef]

15. Tong, Y.; Bai, S.; Zhang, H.; Ye, Y. Rhenium coating prepared on carbon substrate by chemical vapor deposition. Appl. Surf. Sci. 2012, 261, 390-395. [CrossRef]

16. Huang, Y.; Bai, S.; Zhang, H.; Ye, Y. Sealing of cracks in the rhenium coating on C/C composites by alloying with cobalt. Surf. Coat. Technol. 2015, 261, 404-410. [CrossRef]

17. Mercier, S.; Boivin, D.; Bacos, M.P.; Josso, P. A Novel Duplex Re-NiW Based Diffusion Barrier on a Nickel-Base Superalloy for TBC Systems. Mater. Sci. Forum 2008, 595-598, 127-134. [CrossRef]

18. Yu, C.T.; Liu, H.; Ullah, A.; Bao, Z.B.; Zhu, S.L.; Wang, F.H. High-temperature performance of (Ni,Pt)Al coatings on sec-ondgeneration Ni-base single-crystal superalloy at $1100{ }^{\circ} \mathrm{C}$ : Effect of excess S impurities. Corros. Sci. 2019, 159, 108115. [CrossRef]

19. Barin, I. Cl-Cu2Te. In Thermochemical Data of Pure Substances; Wiley-VCH: Weinheim, Germany; New York, NY, USA; Basel, Switzerland, 1995; pp. 524-634.

20. Das, D.K.; Murphy, K.S.; Ma, S.; Pollock, T.M. Formation of Secondary Reaction Zones in Diffusion Aluminide-Coated Ni-Base Single-Crystal Superalloys Containing Ruthenium. Metall. Mater. Trans. A 2008, 39, 1647-1657. [CrossRef]

21. Rae, C.; Hook, M.; Reed, R. The effect of TCP morphology on the development of aluminide coated superalloys. Mater. Sci. Eng. A 2005, 396, 231-239. [CrossRef]

22. Suzuki, A.S.; Rae, C.M.F. Comparison of microstructural evolution in Pt aluminised Ni based superalloys with and without Ru. Mater. Sci. Technol. 2013, 29, 726-732. [CrossRef]

23. Das, D.K.; Gleeson, B.; Murphy, K.S.; Ma, S.; Pollock, T.M. Formation of secondary reaction zone in ruthenium bearing nickel based single crystal superalloys with diffusion aluminide coatings. Mater. Sci. Technol. 2009, 25, 300-308. [CrossRef]

24. Murakami, H.; Sakai, T. Anisotropy of secondary reaction zone formation in aluminized Ni-based single-crystal superalloys. Scr Mater. 2008, 59, 428-431. [CrossRef]

25. Kasai, K.; Murakami, H.; Kuroda, S.; Imai, H. Effect of Surface Treatment and Crystal Orientation on Microstructural Changes in Aluminized Ni-Based Single-Crystal Superalloy. Mater. Trans. 2011, 52, 1768-1772. [CrossRef]

26. Wang, R.; Gong, X.; Peng, H.; Ma, Y.; Guo, H. Interdiffusion behavior between NiAlHf coating and Ni-based single crystal superalloy with different crystal orientations. Appl. Surf. Sci. 2014, 326, 124-130. [CrossRef]

27. Kiruthika, P.; Makineni, S.; Srivastava, C.; Chattopadhyay, K.; Paul, A. Growth mechanism of the interdiffusion zone between platinum modified bond coats and single crystal superalloys. Acta Mater. 2016, 105, 438-448. [CrossRef]

28. Kasai, K.; Murakami, H.; Noda, K. Effect of Thermal History on Microstructural Changes in Aluminized Nickel-Based SingleCrystal Superalloy. Mater. Trans. 2013, 54, 2252-2257. [CrossRef]

29. Nystrom, J.D.; Pollock, T.M.; Murphy, W.H.; Garg, A. Discontinuous cellular precipitation in a high-refractory nickel-base superalloy. Metall. Mater. Trans. A 1997, 28, 2443-2452. [CrossRef]

30. Havrankova, J.; Bursik, J.; Kroupa, A.; Broz, P. Experimental study and thermodynamic assessment of the Ni-Al-Cr-Mo system at 1173 K. Scripta Mater. 2001, 45, 121-126. [CrossRef]

31. Kainuma, R.; Ohnuma, I.; Ishida, K. Partition of alloying elements between $\gamma(\mathrm{L} 12), \eta(\mathrm{DO} 24), \beta$ (B2) and H(L21) phases in the Ni-AI-Ti base systems. J. Chim. Phys. Phys. Chim. Biol. 1997, 94, 978-985. [CrossRef]

32. Huang, W.; Chang, Y.A. A thermodynamic description of the Ni-Al-Cr-Re system. Mater. Sci. Eng. A 1999, 259, 110-119. [CrossRef]

33. Campbell, C.; Boettinger, W.; Kattner, U. Development of a diffusion mobility database for Ni-base superalloys. Acta Mater. 2002, 50, 775-792. [CrossRef] 
34. Wöllmer, S.; Zaefferer, S.; Göken, M.; Mack, T.; Glatzel, U. Characterization of phases of aluminized nickel base superalloys. Surf. Coat. Technol. 2003, 167, 83-96. [CrossRef]

35. Ning, B.; Weaver, M. A preliminary study of DC magnetron sputtered NiAl-Hf coatings. Surf. Coat. Technol. 2004, 177-178, 113-120. [CrossRef] 